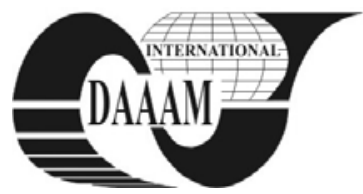

Annals of DAAAM for 2011 \& Proceedings of the 22nd International DAAAM Symposium, Volume 22, No. 1, ISSN 1726-9679 ISBN 978-3-901509-83-4, Editor B. Katalinic, Published by DAAAM International, Vienna, Austria, EU, 2011 Make Harmony between Technology and Nature, and Your Mind will Fly Free as a Bird Annals \& Proceedings of DAAAM International 2011

\title{
RAPID PROTOTYPING IN CASTING TECHNOLOGY: CASE STUDY
}

\author{
BILEK, O[ndrej] \& ROKYTA, L[ubos]
}

\begin{abstract}
Rapid prototyping is a method of instant part production from computer data. Rapid prototyping replaces the currently used methods of machining on CNC machines. The benefit of this method is the immediate preparation of casting patterns for the production of casting mould cavities. The article focuses on the application of this technology for the preparation of models for casting in rubber moulds. A computer model was designed with Inventor software. Prototyping model for casting was printed at the $3 D$ printer Objet 250 Eden.
\end{abstract}

Key words: rapid prototyping, casting, mould, model, $C A D$

\section{INTRODUCTION}

Development in the casting technology is historically moving towards the increasing accuracy, surface quality and dimensional complexity, with increasing requirements for mechanical and physical properties (Jurko et al., 2008), all necessarily with an effort to decrease the material and energy costs. Current casting opportunities are greater thanks to the advances in metallurgy, mould production and quality management system (Cosma et al., 2009). Further advancements are offered with the growing use of computer technology and derived methods (Stanek et al. 2009), such as rapid prototyping technology. The benefit of this technology is the speed of part production - prototyping on the basis of computer data. Application of rapid prototyping (RP) technology in casting technology (Tut et al., 2010) removes the chip working methods in the model production (Fig. 1). The technology has the disadvantage in quite expensive prototype creation; thus casting effort is to develop models of casting patterns with the smallest volume possible. Preparation of casting pattern by RP methods pattern is mainly based on the weight / volume of the model.

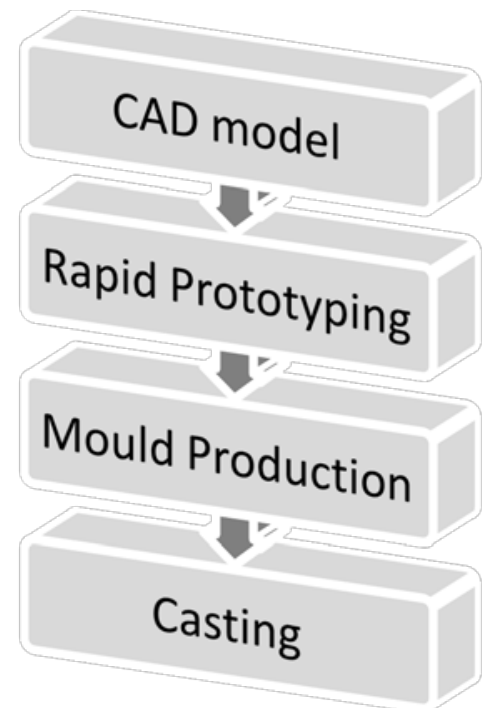

Fig.1. Simplified manufacturing process of casting technology

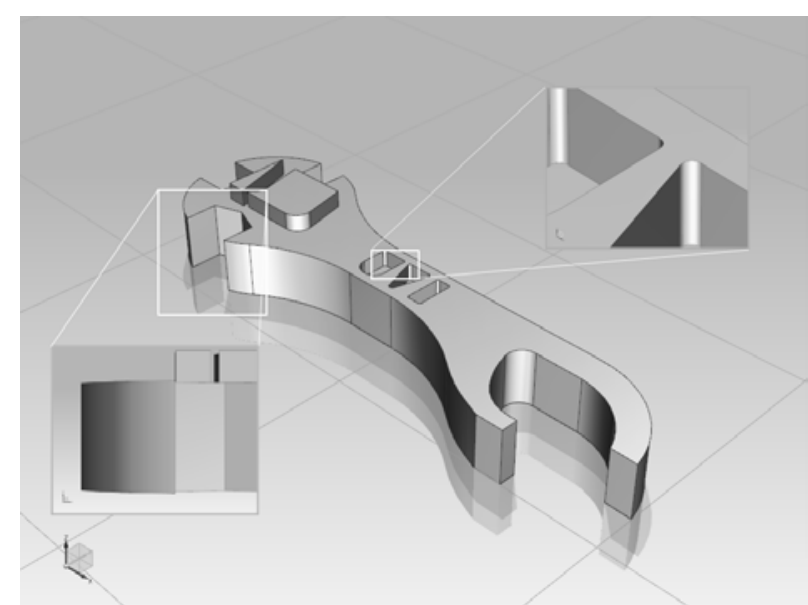

Fig.2. CAD part of glass opener with torque spanner

\section{CASE STUDY}

\subsection{CAD Model and Rapid Prototyping}

For the purpose of this study the model was developed using CAD software Inventor Profesional. Requiremetns for the part were not only estetics but also functional; for this reason the part of torque spanner with bottle opener with symbol of TBU in Zlín, Dep. of Production Engineering was chosen (Fig. 2). The first step is to create model according to the mechanical drawing. This model is, however, unsuitable for casting technology. It includes critical areas, such as sharp angles and transitions, where the melt does not run into, and perpendicular walls to the casting plane causing difficulty of casting removal from mould. The next step is to convert the model of glass opener into the casting pattern with respect to the technological adjustment. Casting pattern contains:

- Linear shrinkage ratio of the casting material

- Applying casting drafts

- Radius and fillet of the edges

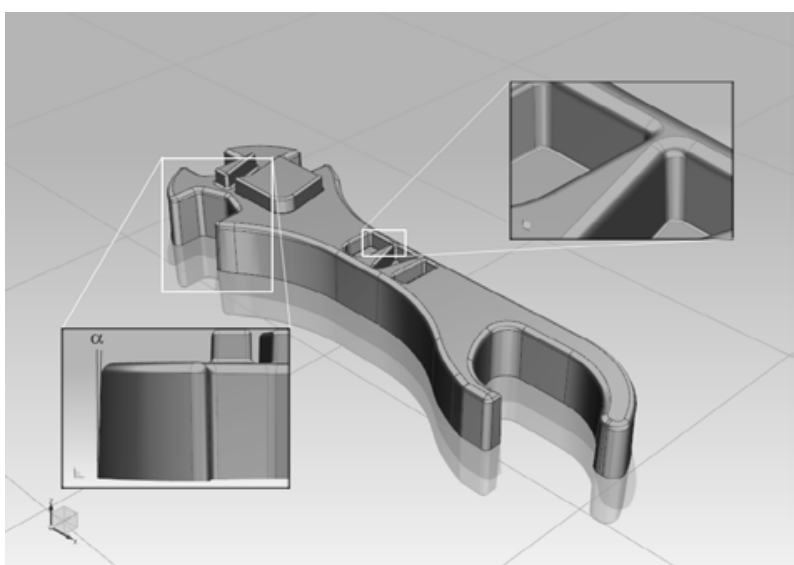

Fig. 3. Casting pattern created from CAD part 
After adjusting the model, casting pattern is prepared. The volume of the casting pattern compared with the model of the part is higher due to the application of casting adjustments (Fig. 3). It should be noted that the model is designed for a specific casting material. During the solidification of the molten material shrinkage occurs. Casting pattern is enlarged by a constant value of linear shrinkage during solidification.

Before printing, casting pattern has to be converted into the STL data as the input format of rapid prototyping printer. Concerning the building material the printer Objet 250 Eden uses material with the trade name VeroWhite and as supporting material the gel based material FullCure ${ }^{\circledR 705}$ Support. Printer technology creates a model by the FDM method, so that the building material is applied in layers and cured by UV radiation.

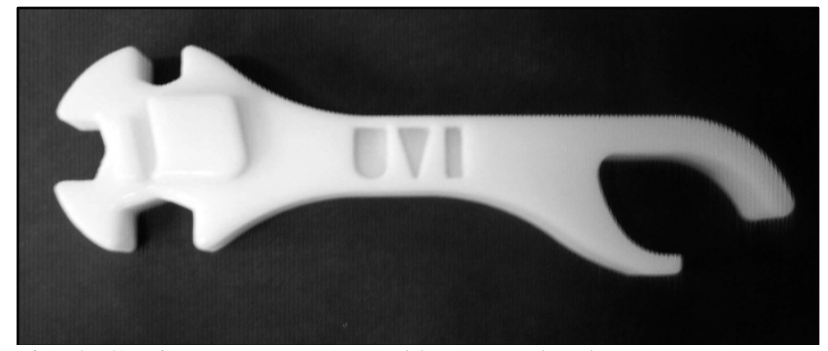

Fig. 4. Casting pattern prepared by RP technology

After printing, the casting pattern (Fig. 4.) must be purged from the supporting material, which function is easy separation of casting pattern from the removable pad, protection the model, and filling hollows; it also allows printing of horizontal holes.

\subsection{Mould Production and Casting}

Generally, printed casting pattern serves as a matrix for creating mould cavity. Mould was created from material Lukopren N 1522. It is a two component silicone rubber of condensing type. After mixing the catalyst, the vulcanization of all material occurs within a few hours to form silicone rubber that has no adhesion to the substrate. Formation takes place so that the bottom plane of the casting pattern is coincident with the casting plane. The model is placed on a flat plate with a frame around the perimeter of the model. This is followed by weighting out the catalyst; the casting pattern is flooded by this material. After vulcanization, model is removed and mould is cleaned and mould cavity is ready for casting (Fig. 5).

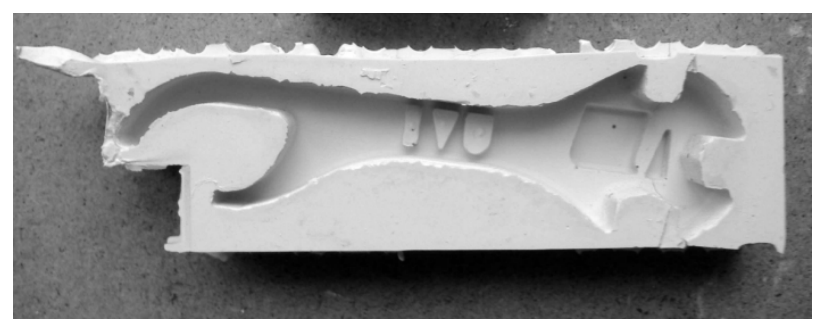

Fig. 5. Mould cavity from silicone material

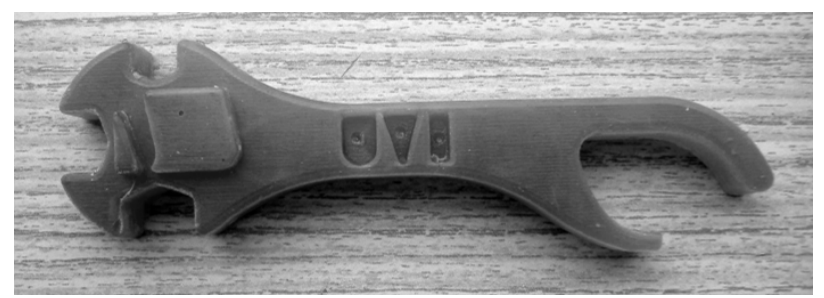

Fig. 6. Cast part created using rapid prototyping technology

The cast materials were tin and wax analogous to Valentan (2008). Casting material was warmed up to the pouring temperature and cast into the prepared mould cavity. After cooling, it was possible to remove casting and process should be repeated. In the case of tin casting, defects were formed in the shape of small cavities and trapped air. These defects were not observed in the wax casting.

\section{CONCLUSION}

In the manufacturing process using rapid prototyping technology creates computer technique direct link among design, modelling and manufacturing. This link is known as Direct Digital Manufacturing - DDM. An application of RP is a new approach for casting technology and allows replacing the machining method for preparation of casting patterns. Production using rapid prototyping in comparison to the manufacturing by CNC machine for a part of the bottle opener is a time-efficient by the reduction of idle times. The designer must consider the technical capabilities of rapid prototyping printer, its resolution and the smallest steps. In assessing the choice of the rapid prototyping technology, the volume of casting pattern is evaluated. For the reason of expensive building material for RP, short-run production of minimal volume of the pattern casting but complex shape is optimal. Advantages of rapid prototyping:

- Production of functional parts of complex shape

- Speed of model preparation

- Various building materials with different dye

- Production from computer data

The main disadvantages of rapid prototyping technologies are:

- Purchase cost and price of building materials

- Dimension limitation of printed models

- Accuracy dependance on the used RP technology

The application of RP is possible, as was illustrated in the presented paper, for the production of semipermanent and also nondurable casting moulds.

\section{REFERENCES}

Cosma, C.; Dume, A.; Tulcan, A. \& Iclanzan, T. (2009). Rapid Development of Products using the Technique of Reverse Engineering, Annals of DAAAM for 2009 \& Proceedings of the 20th International DAAAM Symposium, 25-28th November 2009, Vienna, Austria, ISBN 978-3-901509-704, Katalinic, B. (Ed.), pp. 0347-0348, Vienna

Jurko, J. \& Lukovics, I. (2008). Obrábatelnost' materiálov. TBU, ISBN 978-80-7318-736-1, Zlín

Monkova, K. \& Monka, P. (2009). Process of unknown variable fillet definition realized in order to substitute hand production by NC manufacturing, Annals of DAAAM for 2009 \& Proceedings of the 20th International DAAAM Symposium, 25-28th November 2009, Vienna, Austria, ISBN 978-3-901509-70-4, Katalinic, B. (Ed.), Vienna

Stanek, M.; Manas, M.; Manas, D. \& Sanda, S. (2009). Plastics parts design supported by reverse engineering and rapid prototyping. Chemicke Listy, Vol. 103, No.13, pp. 88-91, ISSN 1213-7103

Suba, O.; Sykorova, L. \& Malachova, M. (2010). Modeling of Transient Thermal Stress in Layered Walls. Manufacturing Technology, vol. 10, pp. 16-19. ISSN 1213-2489

Tut, V. A.; Rotar, I. D.; Cosma, C. \& Cioana, C. (2010). Obtaining Mould Inserts Cavities Using Rapid Prototyping Techniques, Annals of DAAAM for 2010 \& Proceedings of the 21st International DAAAM Symposium, 20-23rd October 2010, Zadar, Croatia, ISSN 1726-9679, ISBN 9783-901509-73-5, Katalinic, B. (Ed.), pp. 1269-1270, Vienna

Valentan, B.; Drstvensek, I.; Brajlih, T.; Hribernik, A. \& Balic, J. (2008). Investment Casting WAX Part Cooling Time Determination, Annals of DAAAM for 2008 \& Proceedings of the 19th International DAAAM Symposium, 22-25th October 2008, Trnava, Slovakia, ISBN 978-3-901509-68-1, Katalinic, B. (Ed.), pp. 1537-1538, Vienna 